\title{
Change in Editor-in-Chief and Editorial Board: new aims and scope of the journal
}

\author{
Pier Luigi Porta
}

Published online: 12 February 2009

(C) Springer-Verlag 2009

The International Review of Economics (IREC) opens its 56th volume with a new Editor and significant changes in the Associate Editors and Advisory Board.

In taking up the editorship of IREC with the present issue, I wish to point out that the journal will continue as a high-quality international forum for economists, covering the whole range of theoretical and applied topics coming under the wide denominator of micro and macroeconomic subjects. At the same time, it will be the aim of the journal to encourage a special emphasis on some of the themes that have emerged in recent developments of economic thought.

A number of recent developments of welfare economics, both in theoretical analysis and applications, have questioned traditional views on economic rationality. Research has advanced in various directions. For example, a vigorous new wave of research has been exploring the common ground shared by economists and psychologists. Quite a number of significant insights from psychological research have come to be integrated into economic theory. A sub-discipline has emerged from the process, behavioural economics, which sheds new light on rational choice issues, in theory and applications, and has contributed-amongst other things- to establish the field of experimental economics. At the same time the range of econometric applications has largely expanded in the analysis of case studies and in making use of the increasing production of empirical evidence.

A different line of investigation has been bringing the analysis of the motivations of human action into focus and has directly questioned the standard assumption that individual preferences are given. The latter assumption disregards the possible changes in preferences which can be determined, for instance, by the influence of interpersonal relations. The simplest case in which the assumption of fixed preferences applies is provided by self-interest, which is, moreover, the standard

\section{P. L. Porta $(\bowtie)$}

Dipartimento di Economia Politica, Universita di Milano-Bicocca,

Piazza dell' Ateneo Nuovo, 1, 20126 Milan, Italy

e-mail: pierluigi.porta@unimib.it 
assumption of the economists who introduced the marginal utility approach. Whenever the issue is taken up in a non-reductionist way, it appears clear that the assumption of self-interested subjects in economics may not be sufficient to support the whole range of ideas which touch on altruism and, more generally, on otherregarding behaviour. That is why new theoretical directions have been developing regarding the way motivations to action are formed and transmitted in society, through imitation and other kinds of influence such as persuasion. This is sometimes called the economics of interpersonal relations. It involves, from a methodological point of view, interactions between economics and philosophy or between economics and the social sciences.

A number of examples can be given on the resulting directions of research stemming from different lines of investigation ranging from reciprocity, to happiness, formal and informal institutions, without limiting the analysis within the realm of the self-interest view of the economic man and the mere logic, albeit important, of the incentive-compatibility of human action.

This journal proposes to adopt a pluralist approach to economics, which appears to be in line with a well-known aphorism of John Stuart Mill: "A person, Mill wrote, is not likely to be a good economist who is nothing else". The challenge of being an economist implies a bent for interaction and interdisciplinary analysis. In recent years, the above-mentioned perspectives of research have given rise to civil economy as a field of research, implying a multi-disciplinary approach to be applied in principle to all kinds of economic problems. This journal aims at opening up to new fields of investigation going beyond economic purism.

The above lines and purposes are the product of continuous interactions, at the University of Milano-Bicocca and elsewhere, with a number of colleagues and institutions and particularly with the previous editor, Aldo Montesano of the Bocconi University of Milan. I wish to express my deep gratitude to Aldo Montesano, as a fine scholar and the editor of this journal for the past 25 years, along with Anna Bagiotti, who has worked so effectively as the Managing Editor.

IREC can be proud of its past and look with great confidence at its future. 